\title{
Erratum zu: Soziologie der Gewalt
}

\section{Andreas Braun}

Online publiziert: 6. Juli 2021

(C) Der/die Autor(en) 2021

\section{Erratum zu:}

\section{Köln Z Soziol 2020}

https://doi.org/10.1007/s11577-020-00688-X

Der Artikel „Soziologie der Gewalt“ von Andreas Braun wurde ursprünglich Online First ohne „Open Access“ auf der Internetplattform des Verlags publiziert. Nach der Veröffentlichung in Bd. 72 Heft 2 pp. 325-328 hatte sich der Autor für eine „Open-Access“-Veröffentlichung entschieden. Das Urheberrecht des Artikels wurde deshalb in (C) Der/die Autor(en) 2021 geändert.

Funding Funding Open Access funding enabled and organized by Projekt DEAL.

Open Access Dieser Artikel wird unter der Creative Commons Namensnennung 4.0 International Lizenz veröffentlicht, welche die Nutzung, Vervielfältigung, Bearbeitung, Verbreitung und Wiedergabe in jeglichem Medium und Format erlaubt, sofern Sie den/die ursprünglichen Autor(en) und die Quelle ordnungsgemäß nennen, einen Link zur Creative Commons Lizenz beifügen und angeben, ob Änderungen vorgenommen wurden.

Die in diesem Artikel enthaltenen Bilder und sonstiges Drittmaterial unterliegen ebenfalls der genannten Creative Commons Lizenz, sofern sich aus der Abbildungslegende nichts anderes ergibt. Sofern das betreffende Material nicht unter der genannten Creative Commons Lizenz steht und die betreffende Handlung nicht nach gesetzlichen Vorschriften erlaubt ist, ist für die oben aufgeführten Weiterverwendungen des Materials die Einwilligung des jeweiligen Rechteinhabers einzuholen.

Die Online-Version des Originalartikels ist unter https://doi.org/10.1007/s11577-020-00688-x zu finden.

Andreas Braun $(\bowtie)$

Fakultät für Soziologie, Universität Bielefeld

Universitätsstr. 25, 33615 Bielefeld, Deutschland

E-Mail: andreas.braun@uni-bielefeld.de 
Weitere Details zur Lizenz entnehmen Sie bitte der Lizenzinformation auf http://creativecommons.org/ licenses/by/4.0/deed.de.

Andreas Braun, Dr., Mitarbeiter in den Arbeitsbereichen Soziologische Theorie und Organisationssoziologie an der Fakultät für Soziologie der Universität Bielefeld. Forschungsschwerpunkte: Soziologische Theorien, Handlungstheorien, Gewaltsoziologie, Neurosoziologie. Aktuelle Publikationen: Gewaltsoziologie im Wandel. Über Situationen, Prozesse und Ordnungen als Bestandteile zur Erforschung von Gewalt. Österreichische Zeitschrift für Soziologie 45, 2020; Interpersonal Violence as an Intrinsic Part of The Civilizing Process: A Neurosociological Approach. European Journal of Sociology 60, 2019; Zur Entdeckung verkörperter Gewalt. 